\title{
Tensile deformation temperature impact on microstructure and mechanical properties of AISI 316LN austenitic stainless steel
}

\author{
Yi Xiong ${ }^{\mathrm{a}, b^{*}}$, Tiantian $\mathrm{He}^{\mathrm{a}}$, Yan $\mathrm{Lu}^{\mathrm{a}}$, Fengzhang Ren ${ }^{\mathrm{a}, \mathrm{b}}$, Alex A. Volinsky ${ }^{\mathrm{c}}$, Wei $\mathrm{CAO}^{\mathrm{d}}$ \\ a School of Materials Science and Engineering, Henan University of Science and Technology, \\ Luoyang 471023, China \\ ${ }^{\mathrm{b}}$ Collaborative Innovation Center of Nonferrous Metals, Luoyang 471023, China \\ ${ }^{c}$ Department of Mechanical Engineering, University of South Florida, Tampa FL 33620, USA \\ ${ }^{\mathrm{d} N a n o}$ and Molecular Systems Research Unit, University of Oulu, FIN-90014, Finland \\ Corresponding author. Tel.: +86 379 64231269; fax: +86 37964231943. \\ E-mail address: xy_hbdy@163.com (Yi Xiong)
}

Abstract: Uniaxial tensile tests were conducted on AISI 316LN austenitic stainless steel from $40^{\circ} \mathrm{C}$ to $300^{\circ} \mathrm{C}$ at a rate of $0.5 \mathrm{~mm} / \mathrm{min}$. Microstructure and mechanical properties of the deformed steel were investigated by optical, scanning and transmission electron microscopies, X-ray diffraction, and microhardness testing. The yield strength, ultimate tensile strength, elongation and microhardness increase with the decrease of the test temperature. The tensile fracture morphology has the dimple rupture feature after low temperature deformations, and turns to a mixture of transgranular fracture and dimple fracture after high temperature ones. The dominating deformation microstructure evolves from dislocation tangle/slip bands to large deformation twins/slip bands with temperature decrease. The deformation-induced martensite transformation can only be realized at low temperature, and its quantity increases with the decrease of the temperature.

Keywords: AISI 316LN austenitic stainless steel; microstructure; mechanical properties; deformation-induced martensite transformation 


\section{Introduction}

Endowed with intergranular corrosion resistance, high tensile strength at elevated temperature, and creep strength, the $316 \mathrm{LN}$ austenitic stainless steel is widely used in nuclear power plants as a structural material at crucial places such as the main pipeline, heat exchanger, and bolted flange connections $[1,2]$. It is well known that solid state transformations do not take place during heating processes. For this reason, forging is needed to improve microstructure and mechanical properties of $316 \mathrm{LN}$ austenitic stainless steel. However, the narrow window of the forging temperature and relatively high deformation resistance limit its wide applications in the $316 \mathrm{LN}$ austenitic stainless steel treatments. For these reasons, many researches were mainly focused on rheological behavior and microstructure evolution of $316 \mathrm{LN}$ austenitic stainless steel during hot deformations. Poliak et al [3-5] studied dynamic recrystallization behavior of 316LN austenitic stainless steel during hot deformation. There was a deflection in the true stress-strain curves and the deflection point represented the beginning of dynamic recrystallization. Byun et al[6]studied the impacts of irradiation, test temperature and strain on the deformation microstructure of $316 \mathrm{LN}$ austenitic stainless steel. Deformation microstructure changed from a dominant feature of dislocation tangle to the large stacking fault/twin band when increasing radiationdose and strain, or decreasing test temperature. The tensile deformation behavior of $316 \mathrm{LN}$ austenitic stainless steel was also revealed at room and high temperatures[7]. These findings provided useful guidelines for processing and service of $316 \mathrm{LN}$ austenitic stainless steel components at high temperature.

Early studies showed the yield strength was slightly influenced by strain rate and temperature, but ultimate tensile strength was affected significantly during cryogenic tensile tests [8]. Similar results were also observed in experiments with austenitic stainless steel plates [9]. Behjati [10] stated 
that the yield strength is less vulnerable to the temperature, while the ultimate tensile strength is greatly influenced by temperature. In Refs. [11-13], it has been generally found that the elongation of $316 \mathrm{LN}$ austenitic stainless steel at low temperature is much higher than that at room temperature. In spite of the prior works, however, there is a lack of systematic studies of the microstructure evolution of 316LN austenitic stainless steel in static or quasi-static conditions at operating temperature and low temperature. The deficient knowledge limit the application range of 316LN austenitic stainless steel. Additionally, the deformation-induced martensite transformation has not been considered during service time.

In this paper, uniaxial tensile tests from $-40^{\circ} \mathrm{C}$ to $300^{\circ} \mathrm{C}$ were conducted on $316 \mathrm{LN}$ austenitic stainless steel, and the corresponding microstructure evolution and mechanical properties changes were systematically investigated. The results discussed in this paper can provide useful experimental support for the development and applications of $316 \mathrm{LN}$ austenitic stainless steel.

\section{Materials and experimental procedure}

Vacuum induction furnace was used to manufacture the investigated $150 \mathrm{~kg}$ steel ingot with the following chemical composition (in wt.\%): $0.01 \mathrm{C}, 0.49 \mathrm{Si}, 0.87 \mathrm{Mn}, 17.09 \mathrm{Cr}, 14.04 \mathrm{Ni}, 2.56 \mathrm{Mo}$, $0.14 \mathrm{~N}$ and $\mathrm{Fe}$ balance. The ingot was hot forged down to a $15 \mathrm{~mm}$ thick slab. The slab was then heat treated at $1050{ }^{\circ} \mathrm{C}$ for $2 \mathrm{~h}$. After solution treatment, the tensile test specimens with a gage length of $15 \mathrm{~mm}, 3 \mathrm{~mm}$ wide and $1 \mathrm{~mm}$ thick were prepared along the longitudinal direction, as shown in Fig. 1. The uniaxial tensile tests were conducted by using UTM4104 electronic universal testing machine with a sealed environmental chamber. The low temperature was adjusted with liquid nitrogen under flow control, while the high temperature was kept using a resistance heating wire. The test temperatures were $-40^{\circ} \mathrm{C},-20^{\circ} \mathrm{C}, 25^{\circ} \mathrm{C}$ (room temperature), $100^{\circ} \mathrm{C}, 200^{\circ} \mathrm{C}$ and $300^{\circ} \mathrm{C}$, respectively. 
The tensile rate was $0.5 \mathrm{~mm} / \mathrm{min}$. The morphology of the fracture surfaces was observed using a scanning electron microscope (SEM, JSM-5610LV), operated at $20 \mathrm{kV}$. The average dimple size was determined by intercept method. Microstructure characterization near tensile fracture zone was carried out via optical microscopy (OLYMPUS PMG3) and transmission electron microscopy (TEM, JEM-2010). For metallographic examination, samples were prepared by chemical corrosion using aqua regia. For the TEM study, mechanically thinned $50 \mu \mathrm{m}$ discs were prepared using twin gun precision ion polishing system (Gatan, model 691). The operating voltage of TEM was $200 \mathrm{kV}$.

The X-ray diffraction (XRD) experiments were carried out on the D/MAX 2400 X-ray diffractometer. The tube voltage and current were $35 \mathrm{kV}$ and $40 \mathrm{~mA}$, respectively. The $\mathrm{CuK}_{\alpha 1}$ $(\lambda=0.15406 \mathrm{~nm})$ beam was tuned with a diameter of $\sim 2 \mathrm{~mm}$ as the incident source. The scan angle range was $40-100^{\circ}$ at a speed of $0.02^{\circ} /$ s. Using the $(200)_{\gamma},(220)_{\gamma},(311)_{\gamma},(200)_{\alpha^{\prime}},(211)_{\alpha^{\prime}},(220)_{\alpha^{\prime}}$ reflections, the volume fraction of $\alpha^{\prime}$-martensite was calculated through the following equation:

$\mathrm{V}_{\alpha}=\frac{1 / \mathrm{n} \sum_{\mathrm{j}=1}^{\mathrm{n}} \mathrm{I}_{\alpha^{\prime}}^{\mathrm{j}} / \mathrm{R}_{\alpha^{\prime}}^{\mathrm{j}}}{1 / \mathrm{n} \sum_{\mathrm{j}=1}^{\mathrm{n}} \mathrm{I}_{\alpha^{\prime}}^{\mathrm{j}} / \mathrm{R}_{\alpha^{\prime}}^{\mathrm{j}}+1 / \mathrm{n} \sum_{\mathrm{j}=1}^{\mathrm{n}} \mathrm{I}_{\gamma}^{\mathrm{j}} / \mathrm{R}_{\gamma}^{\mathrm{j}}}$

Here, n, I, R represent the diffraction number, diffraction intensity, and scattering factor, respectively. An average volume fraction of $\alpha^{\prime}$-martensite was determined based on 3 measurements. Microhardness was measured using the MH-3 Vickers microhardness tester with $200 \mathrm{~g}$ normal load and $10 \mathrm{~s}$ holding time. The microhardness was averaged from values given by 5 indentation measurements. After grinding and polishing the tensile fracture surface, the microhardness tests were carried out at $1 \mathrm{~mm}$ distance from the fracture surface.

\section{Results}

\subsection{Temperature dependence of engineering stress-strain curves}


Fig. 2 shows the engineering stress-strain curves of 316LN austenitic stainless steels under different temperatures. It can be seen that the curves are quite similar. The steel showed strong temperature dependences for the strength and elongation. As the test temperature decreased from $300{ }^{\circ} \mathrm{C}$ to $-40{ }^{\circ} \mathrm{C}$, the ultimate tensile strength (UTS) and the yield strength(YS) increased by $84 \%$ and $67 \%$, from $345 \mathrm{MPa}$ and $134 \mathrm{MPa}$ to $635 \mathrm{MPa}$ and $224 \mathrm{MPa}$, respectively. As expected, the yield strength and ultimate tensile strength increased with the decrease of the test temperature. However, the speed of changes was different between the yield strength and ultimate tensile strength. Following the temperature decrease, the yield strength increased slightly, while the ultimate tensile strength increased rapidly. This is consistent with other studies [8-10]. The elongation at $-40{ }^{\circ} \mathrm{C}$ was obviously higher than at $300{ }^{\circ} \mathrm{C}$, and enhanced from $37 \%$ to $92 \%$. This is in line with similar observation as reported in refs. [11-13].

As shown in Fig. 3, both YS and UTS reversely increased with temperature. The strength properties (UTS) as well as the elongation were noticeably enhanced at lower test temperature. These increases can normally be due to the formation of face centered cubic (FCC) materials, at the present stage, the deformation-induced martensite [14-17]. The volume fraction of martensite increases when lowering the test temperature[18], resulting in increases of the YS and the UTS due to composite strengthening by continuous refinement of the martensite and austenite mixture [1921]. The present results support the aforementioned claims. A large increase in elongation up to $92 \%$ indicates a deviation from the normal FCC material behavior. The UTS, YS, and elongation are found to increase with the martensite volume fraction. In general, the uniform elongation should increase when more stress-induced obstacles, such as large stacking faults, twins and martensite laths are formed [19].During the deformation, less uniform elongation will be yielded when tangled 
dislocation networks are dominant.

\subsection{Deformation microstructure near tensile fracture}

Figs. 4 and 5 show OM and TEM images of microstructure near the tensile fracture. After solution treatment, the microstructure was equiaxed austenite grains with the size of about $50 \mu \mathrm{m}$. Additionally, in local area a small amount of annealing twins was also observed as shown in Fig. 4a. After room temperature tensile test, deformed grains with slide lines turned out (Fig. 4b). The direction of the slip bands was different among the grains, presenting a typical feature of metals with low stacking fault energy $[22,23]$. When the temperature increased to $300{ }^{\circ} \mathrm{C}$, the number of the slip bands reduced and a small amount of annealing twins turns up in the deformed grains. The degree of deformation was smaller than that at room temperature and the austenite grain size increased to $60-70 \mu \mathrm{m}$, as shown in Fig. $4 \mathrm{c}$. When the test temperature was tuned to $-40{ }^{\circ} \mathrm{C}$, the number of slip bands obviously increased. Interactions happened between slip bands with different directions, resulting in elongated austenite grains. The martensitic structure was formed in the deformed microstructure. The deformation degree was higher than that at room temperature. The corresponding microstructure was identified in Fig.4d.

Fig.5a and $\mathrm{b}$ show that at room temperature there was deformation mainly accomplished by slip bands and dislocation substructures, along with a small amount of deformation twins. Moreover, dislocations moved easily and were annihilated because of dislocation-dislocation interactions during the movement. This resulted in indistinct sliding boundaries and lowered dislocation density in steel, along with local area high-density dislocation loops and tangled networks. For example, this microstructure was observed at $300^{\circ} \mathrm{C}$ in Fig. $5 \mathrm{c}$ and d. Similar results for microstructure evolution of $316 \mathrm{LN}$ stainless steel during creep and fatigue were obtained by Prasad Reddy et 
al[24]. With the temperature reduced to $-40{ }^{\circ} \mathrm{C}$, the deformed microstructure was similar with that at room temperature. Under this condition, while the quantities of slip bands and dislocation substructures declined slightly, the number of deformation twins increased rapidly. Meanwhile, deformation twins with different directions interacted, as seen in Fig. 5 e and f. The nucleation sites were provided by the joint impacts from the suppression of temperature rise of the samples at low test temperature and the twin-dislocation intersection. As a result, the amount of martensite transformation increases.

\subsection{XRD analysis}

The XRD patterns of $316 \mathrm{LN}$ austenitic stainless steel after uniaxial tensile tests at different temperatures are shown in Fig. 6.Compared with the samples without deformation, no additional diffraction peaks were not found when the deformation temperature was above the room temperature. The deformation-induced martensitic transformation did not occur in the $316 \mathrm{LN}$ austenitic stainless steel after tensile deformation under this condition. As the temperature was reduced to $-20{ }^{\circ} \mathrm{C}$ and $-40{ }^{\circ} \mathrm{C}$, diffraction peaks of the $\alpha^{\prime}$-martensite were present near the fracture surface of austenitic stainless steel. The fraction of $\alpha^{\prime}$-martensite transformation increased from $17.3 \%$ $\left(-20^{\circ} \mathrm{C}\right)$ to $34.9 \%\left(-40^{\circ} \mathrm{C}\right)$. Meanwhile, deformed at $-40{ }^{\circ} \mathrm{C}$, the amount of $\alpha^{\prime}$-martensite transformation was only $13.6 \%$ at the place $\sim 20 \mathrm{~mm}$ apart from the fracture surface. In fact, the deformation-induced martensitic transformation of 316LN austenitic stainless steel depends on strain, stress, strain rate, deformation temperature and so on. Larger strain leads to more defects, and easier martensite nucleation around the defects [25].Shrinivas et al [26] stated that the martensite of $316 \mathrm{~L}$ austenitic stainless steel nucleated mainly in the intersection area of the shear bands, as influenced by the stacking fault energy. Thus, in order to induce martensitic transformation, 
large strain should be applied to materials. In austenitic stainless steels the formation of martensite has been frequently observed during deformation at room temperature or below [27-29]. In situ observations on Fe-Ni-Cr stainless steels showed that $\varepsilon$-martensite was formed along with stacking faults, while $\alpha^{\prime}$-martensite nucleation seemed to be associated with dislocation pile-ups [28,29]. In the present study, the deformation microstructure formed below room temperature is similar to the one reported in ref. [30]. The amount of $\alpha^{\prime}$-martensite reversely increased with the temperature.

\subsection{Fractography analysis}

Fig. 7 shows the fractography of the $316 \mathrm{LN}$ austenitic stainless steel specimens tested at $40^{\circ} \mathrm{C}, 25^{\circ} \mathrm{C}$ (room temperature) and $300^{\circ} \mathrm{C}$. The SEM observations reveal that the fracture surfaces were completely ductile fracture at low temperature, but turned to a mixture of transgranular fracture and dimple fracture at high temperature. Very similar elongations over $80 \%$ were reached for the 316LN austenitic stainless steel treated equal to and below room temperature. The rates are much higher than these obtained for $100-300{ }^{\circ} \mathrm{C}$, as shown in Fig. 2 and Fig. 3. The sharp decrease of the elongation at higher temperature is mainly due to the slow growth of the austenite grains. This weakens the binding force of the grain boundary and reduces the plasticity and toughness. Similar phenomenon was observed in Ref. [7], where the elongation of 316LN austenitic stainless steel was

about $40 \%$ at $100-700{ }^{\circ} \mathrm{C}$. After treated at $300{ }^{\circ} \mathrm{C}$, the fracture surface possesses several large and deep dimples with an average size of $12 \mu \mathrm{m} \pm 3 \mu \mathrm{m}$, and many small and shallow dimples (2 $\mu \mathrm{m} \pm 1 \mu \mathrm{m})$.Choudhary et al [31] stated that due to the dynamic strain aging, a low elongation of $316 \mathrm{LN}$ austenitic stainless steel was formed after deformation at $300{ }^{\circ} \mathrm{C}$. When test temperature was reduced to $25^{\circ} \mathrm{C}$, a large amount of small and shallow dimples was observed on the fracture surface. In local area a small amount of large and deep dimples stayed at the bottom of the large dimples, 
denoting the possible formation of secondary phase particles. Further decreasing the test temperature to $-40{ }^{\circ} \mathrm{C}$, the steel possesses large and deep dimples at the fracture surface and some secondary phase particles at the bottom of the dimples. This indicated that the $316 \mathrm{LN}$ austenitic stainless steel had better toughness via low temperature deformation. The present results are consistent with the findings of Qin et al[13]. In their studies, the elongation tested at $77 \mathrm{~K}$ was higher than that at $300 \mathrm{~K}$. Similar results were also reported in Ref. [6], and attributed to substantial difference of strain hardening rate under different tensile temperatures. For the room temperature test, the elongation decreased by cold working. However, the trend does not apply to the cryogenic test, indicating the limited influences on cryogenic elongation at failure from the cold working. Ref. [18] proposed a possible micro-mechanism to explain the void growth kinetics in austenitic stainless steels. Deformation-induced martensite affects the void growth characteristics by the factors of (i) retardation of void nucleation at early transformation softening, and(ii) counteraction of the strain softening effect due to void growth by transformation hardening. The decrease in void growth can be explained by the obstruction of void growth due to rapid nucleation of deformation-induced martensite. The enhanced ductility is mainly due to the delayed necking because of the enhanced void nucleation and suppressed void growth(presence of finer voids at $-40^{\circ} \mathrm{C}$ in Fig.7). This phenomenon actually enables material to accommodate a large necking strain.

Fig. 8 shows the surface morphology of the $316 \mathrm{LN}$ austenitic stainless steels specimens after tensile testing at room temperature. It can be seen that severe deformation occurred near to the fracture. The slip bands with different directions interacted with each other and formed wrinkles. Meanwhile, in local areas long and narrow cracks were observed, as indicated by the arrows in Fig. 8a. Fig. $8 \mathrm{~b}$ depicts the surface morphology at a distance of $10 \mathrm{~mm}$ from the fracture zone. The 
wrinkles were formed, but the morphology was mainly wave texture. In the local area, a small amount of cracks existed and most slip bands in the austenite grains were parallel to each other. Fig. 8c shows the magnification of the elliptical area in Fig. $8 \mathrm{~b}$ with wrinkles. The deformation morphology of the $316 \mathrm{LN}$ austenitic stainless steel is $20 \mathrm{~mm}$ away from the fracture surface as shown in Fig. 8d. The deformation in Fig. 8d was smaller than those in Fig. 8a and Fig. 8d.The deformation morphology has the shape of parallel slip bands, and causes kink steps following its non-uniformity (arrows in Fig. 8d).From Fig. 8, it can be concluded that there exists big deformations close to the fracture surface. Meanwhile, more wrinkles can be formed and in local areas of cracks. The similar results were also found in Ref.[32].It stated that the fracture failure of the $316 \mathrm{LN}$ austenitic stainless steel was attributed to the decrease of surface roughness and increase of extensive twinning. Similar phenomenon was observed in-situ SEM tension test of high-nitrogen austenitic stainless steels [33]. The formation of microcracks was due to additional slip systems as a result of the larger space between the slip bands. The surface morphology of the specimens after tensile testing at lower or higher temperature was similar to the room temperature results.

\subsection{Microhardness}

Fig. 9 shows the microhardness of the $316 \mathrm{LN}$ austenitic stainless steels samples near tensile fracture. The microhardness increased with the decrease of the test temperature. Treated with temperature below $25{ }^{\circ} \mathrm{C}$, the steel microhardness changed slowly. The microhardness decreased only by $9.1 \%$ from $396 \mathrm{HV}\left(-40^{\circ} \mathrm{C}\right)$ to $360 \mathrm{HV}\left(25^{\circ} \mathrm{C}\right)$. Meanwhile, once the test temperature was higher than the room temperature, the change of the microhardness was sharp, and the value was reduced by $31.3 \%$, from $360 \mathrm{HV}\left(25^{\circ} \mathrm{C}\right)$ to $247 \mathrm{HV}\left(300^{\circ} \mathrm{C}\right)$. The microhardness near the fracture surface at different test temperatures was obviously higher than that after solid solution treatment 
(170 HV).Compared with the original sample before deformation, the microhardness near the fracture zone increased by $133 \%$ and $45 \%$ when the test temperatures were $-40{ }^{\circ} \mathrm{C}$ and $300^{\circ} \mathrm{C}$. When the test temperature was below room temperature, the deformation microstructure was in the form of dislocation tangles and deformation twins. There were more dislocation tangles closer to the fracture surface. Meanwhile, the interaction of the deformation twins in different orientations occurred, leading to the grain refinement of the austenite matrix structure (Fig. 4d).Besides, the deformation-induced martensite transformation occurred at low temperature and the amount of martensite transformation increased when the temperature dropped. This lead to the large increase of the microhardness near the fracture surface. Similar phenomenon was revealed for the microhardness of the $316 \mathrm{LN}$ austenitic stainless steel after tensile testing under temperature range of 25 to $1000{ }^{\circ} \mathrm{C}[7]$. In that study, the microhardness decreased with the tensile test temperature. However, when the temperature was higher than the room temperature, the deformation microstructure was primarily dislocation tangles and dynamic recovery occurred. Thus, with the combination effect of dislocation strengthening and dynamic recovery, the microhardness at $300{ }^{\circ} \mathrm{C}$ was only $247 \mathrm{HV}$, much lower than the value at $-40{ }^{\circ} \mathrm{C}(396 \mathrm{HV})$.

\section{Discussion}

The present study illustrates microstructure evolutions of $316 \mathrm{LN}$ austenitic stainless steel deformed at different uniaxial tensile test temperatures ranging from $-40^{\circ} \mathrm{C}$ to $300{ }^{\circ} \mathrm{C}$. Experimental results clearly demonstrate that the test temperature significantly affects deformed microstructure characteristics. Depending on the deformation temperature, two types of microstructure were formed after tensile testing at different temperatures. Dominant microstructure changed from dislocation tangle/slip bands to large deformation twins/slip bands with the decrease of the test 
temperature. At the elevated temperature $\left(300{ }^{\circ} \mathrm{C}\right)$, deformation microstructure is consisted of tangled dislocations, indicating that cross-slip occurred during dislocation glide. After the test temperature dropped to room temperature $\left(25^{\circ} \mathrm{C}\right)$, the deformation was mainly accomplished by slip bands and dislocation substructures, along with a small amount of deformation twins. When the test temperature further decreased to $-40{ }^{\circ} \mathrm{C}$, the number of deformation twins obviously increased and the distance of the deformation twins reduced.

Due to the martensitic transformation, the stress concentration during lower temperature tensile testing reduced and cracking was delayed. The deformation-induced martensite transformation occurred at the largest deformation area, which resulted in the strength increase. The deformation became more difficult. The deformation propagated to other areas without martensitic transformations, and postponed the necking formation. The formation and transformation of martensite depended on the accumulation of the strain energy. Due to the transformation induced plasticity(TRIP) effect, the strength and elongation was improved. Sato [34] and Seetharaman [35] found two transformation mechanisms from austenite to martensite. (1) When the stacking fault energy of the base metal was below $18 \mathrm{~mJ} / \mathrm{m}^{2}$, the transformation of martensite follows: $\gamma$ austenite $\rightarrow \varepsilon$-martensite $\rightarrow \alpha^{\prime}$-martensite. (2) When the stacking fault energy of the base metal was higher than $18 \mathrm{~mJ} / \mathrm{m}^{2}$, the transformation of martensite turns to: $\gamma$-austenite $\rightarrow$ twin $\rightarrow \alpha^{\prime}$-martensite. Previous researches [36,37] showed that the stacking fault energy of $316 \mathrm{LN}$ austenitic stainless steels was about $10 \mathrm{~mJ} / \mathrm{m}^{2}$, thus, the transformation of martensite in $316 \mathrm{LN}$ austenitic stainless steel followed the first mechanism. However, the diffraction peak of $\varepsilon$-martensite was not found in the present XRD patterns (Fig. 6), neither from TEM observations (Fig.10). This indicated that $\alpha^{\prime}-$ martensite was mainly formed in $316 \mathrm{LN}$ austenitic stainless steel after low temperature tensile 
deformation. The content of $\varepsilon$-martensite was low, or $\varepsilon$-martensite transition phase eventually transformed to $\alpha^{\prime}$-martensitewith more deformation. Moreover, austenite has coherent relation with martensite and high interfacial energy prevented crack propagation, resulting in elongation increase. With further strain increase and temperature decrease, the dislocation tangles aggravated which prevent the dislocation movement. In order to coordinate the severe plastic deformation, deformation twins were formed. Meanwhile, the subgrain orientation was altered, leading to release of stress concentration. Deformation twins were restricted and interacted with each other, which hindered dislocation motion, forming the twinning induced plasticity(TWIP) effect. The elongation was improved. Under the combination TRIP and TWIP effects, strength and elongation of 316LN austenitic stainless steel at low temperature are significantly higher than that at high temperature. As shown in Fig. 2, once the deformation twins were formed in 316LN austenitic stainless steel, the elongation was high. When the test temperature was below room temperature, the elongation was over $80 \%$. Meanwhile, the elongation was reduced to $40 \%$ when the test temperature was higher than the room temperature. This was mainly due to microstructure changes. When the test temperature was below room temperature, deformation twins were formed and the amount of the deformation twins increased sharply with the test temperature decrease. Besides, the elongation improved by quantity of the martensite is also ascribed to the TRIP effect [38,39]. Under the comprehensive function of TRIP and TWIP effect, the elongation was remarkably increased when decreasing the test temperature. Meanwhile, the elongation of $316 \mathrm{LN}$ austenitic stainless steel significantly increases with the test temperature reduction. When the test temperature was above the room temperature, the microstructure was in the form of dislocation tangles and the deformation twin did not occur, leading to poor work-hardening capacity. As a result, the elongation was 
significantly reduced with the test temperature increase, as shown in Fig. 2.

Twinning can contribute to failure in two ways. For one thing, twinning increases strain hardening and hence accounts for higher ductility[40].Twins may act as a barrier and the dislocations pile up at the boundary, which increases the chance of crack initiation at the sharp ends of the twin. Another possibility arises due to surface roughness [31], which results in further twinning in the adjacent grain, as seen in Fig. 11. Alternatively, it could lead to crack propagation along the grain boundary. Thus, the elongation of $316 \mathrm{LN}$ austenitic stainless steel at low temperature is significantly higher than that at high temperature mainly due to the formation of the deformation twin at low temperature, as shown in Fig. 2.

\section{Conclusions}

To conclude, the 316LN austenitic stainless steel after uniaxial tensile tests were conducted at the $-40-300^{\circ} \mathrm{C}$ temperature range using electronic universal testing machine. The microstructure and mechanical properties were systematically characterized and analyzed. The results are as follows:

1. The deformation-induced martensite transformation only occurs at low temperature, and increases in quantity following the temperature decrease. The corresponding yield strength, tensile strength, microhardness and elongation of $316 \mathrm{LN}$ austenitic stainless steel increase when tuning down the test temperature. The increase of the mechanical properties of 316LN austenitic stainless steel is attribute to the comprehensive function of TRIP and TWIP effect.

2. Deformation microstructure changed from a dislocation tangle/slip bands dominant to a large deformation twins/slip bands dominant with decreasing test temperature. The tensile fracture morphology is dimple rupture at low temperature and a mixture of transgranular fracture and dimple fracture at high temperature. However, the elongation at or below the room temperature can reach about two times higher than the one at high temperatures.

\section{Acknowledgements}


This work was supported by the National Natural Science Foundation of China under grants Nos. 50801021 and 51201061, and by the Program for Science, Technology Innovation Talents in Universities of Henan Province (17HASTIT026), the International Cooperation Project from Henan Province (172102410032), Science and Technology Project of Henan Province (152102210077), Education Department of Henan Province (16A430005) and the Science and Technology Innovation Team of Henan University of Science and Technology (2015XTD006).W. Cao acknowledges financial supports from Center for Advance Steel Research (CASR), University of Oulu.

\section{References}

[1]G.V. Prasad Reddy, R. Kannan , K. Mariappan , R. Sandhya , S. Sankaran , K. BhanuSankaraRao,Effect of strain rate on low cycle fatigue of 316LN stainless steel with varying nitrogen content: Part-I cyclic deformation behavior. International Journal of Fatigue,2015,81: 299-308.

[2]G.V. Prasad Reddy, K. Mariappan, R. Kannan, R. Sandhya , S. Sankaran, K. BhanuSankaraRao, Effect of strain rate on low cycle fatigue of 316LN stainless steel with varying nitrogen content: Part-II fatigue life and fracture. International Journal of Fatigue,2015,81: 309-317.

[3] E.I.Poliak, J.J.Jonas, Initiation of dynamic recrystallization in constant strain rate hot deformation, ISIJ International, 2003, 43(5):684-691.

[4] S.L.Wang, M.X.Zhang, H.C.Wu, B.Yang, Study on the dynamic recrystallization model and mechanism of nuclear grade $316 \mathrm{LN}$ austenitic stainless steel. Materials Characterization,2016,118:92-101.

[5] C.Y. Sun, Y. Xiang, Q.J.Zhou, D. J. Politis, Z.H. Sun, M.Q. Wang, Dynamic recrystallization 
and hot workability of 316LN stainless steel. Metals, 2016, 6(7): 152-164.

[6] T.S.Byun,N.Hashimoto,K.Farrell, Temperature dependence of strain hardening and plastic instability behaviors in austenitic stainless steels, ActaMater., 2004,52:3889-3899.

[7] H.X. Pei, H.L. Zhang, L.X. Wang,et al.Tensile behaviour of 316LN stainless steel atelevated temperatures,Materials at High Temperatures,2014,31(3):198-203.

[8] G.E. Dieter. Mechanical metallurgy. New York: McGraw-Hill; 1976.

[9] W.G. Dobson, D.L. Johnson. Effect of strain rate on measured mechanical properties of stainless steel at 4 K, Adv. Cryogenic Eng. Mater., 1984, 30:185-92.

[10]P.Behjati, A.Kermanpur, A.Najafizadeh, H.SamaeiBaghbadorani. Microstructural investigation on deformation behavior of high purity $\mathrm{Fe}-\mathrm{Cr}-\mathrm{Ni}$ austenitic alloys during tensile testing at different temperatures, Mater.Sci.Eng.A, 2014, 618:16-21.

[11]W.S.Park,S.W.Yoo,M.H.Kim,J.M.Lee, Strain-rate effects on the mechanical behavior of the AISI 300 series of austenitic stainless steel under cryogenic environments, Mater.Des., 2010, 31:3630-3640.

[12]M.Botshekan, S. Degallaix, Y.Desplanques, Influence of martensitic transformation on the lowcycle fatigue behaviour of $316 \mathrm{LN}$ stainless steel at $77 \mathrm{~K}$, Mater.Sci.Eng. A, 1997, 234-236:463466.

[13]J.G.Qin, C. Dai, G.J.Liao, Y.Wu, X.F.Zhu, C.J.Huang, L.F.Li,K.Wang, X.G.Shen, Z.P.Tu, H.Ji, Tensile test of SS 316LN jacket with different conditions, Cryogenics, 2014, 64:16-20.

[14] E. Nagy,V.Mertinger,F.Tranta, J. Sólyom, Deformation induced martensitic transformation in stainless steels, Mater.Sci.Eng.A, 2004, 378:308-313.

[15] A.K.Dey,D.C.Murdoch,M.C.Mataya,J.C.Speer,D.K.Matlock, Quantitative measurement of 
deformation-induced martensite in 304 stainless steel by X-ray diffraction, Scr.Mater., 2004, 50:1445-1449.

[16]A.Das,S.Sivaprasad,M.Ghosh,P.C.Chakraborty,S.Tarafder, Morphologies and characteristics of deformation induced martensite during tensile deformation of $304 \mathrm{LN}$ stainless steel, Mater.Sci.Eng.A, 2008,486:283-286.

[17] H. Roy,A.Ray,K.Barat,C.Hochmuth,S.Sivaprasad,S.Tarafder,U.Glatzel,K.K. Ray, Structural variations ahead of crack tip during monotonic and cyclic fracture tests of AISI 304LN stainless steel, Mater.Sci.Eng.A, 2013, 561:88-99.

[18] K. Barat, H.N.Bar, D.Mandal, H.Royc, S.Sivaprasad, S.Tarafder,Low temperature tensile deformation and acoustic emission signal characteristics of AISI304LN stainless steel,Mater.Sci.Eng.A, 2014, 597:37-45.

[19] G.L. Huang,D.K.Matlock,G.Krauss,Martensite formation, strain rate sensitivity, and deformation behavior of type 304 stainless steel sheet,Metallurgical and Materials Transactions A, 1989, 20:1239-1246.

[20] T.S.Byun,On the stress dependence of partial dislocation separation and deformation microstructure in austenitic stainless steels,Acta Mater., 2003, 51(11):3063-3071.

[21] J.H. Kim,W.S.Park,M.S.Chun,J.J.Kim,J.H.Bae,M.H.Kim,J.M.Lee, Effect of pre-straining on low-temperature mechanical behavior of AISI 304L, Mater.Sci.Eng. A, 2012, 543:50-57.

[22] J.A. Jime'nez, G. Frommeye, Analysis of the microstructureevolution during tensile testing at room temperature of highmanganeseaustenitic steel, Mater. Charact., 2010, 61:221-226.

[23] J. Manjanna, S. Kobayashi, Y. Kamada, S. Takahashi, H.Kikuchi, Martensitic transformation in SUS 316LN austeniticstainless steel at room temperature, J. Mater. Sci., 2008, 43:2659- 
2665.

[24] G.V. Prasad Reddy, R. Sandhya, S. Sankaran, P. Parameswaran, K. Laha,Creep-fatigue interaction behavior of $316 \mathrm{LN}$ austenitic stainless steelwith varying nitrogen content,Materials and Design, 2015, 88:972-982.

[25] S.S. Hecker, M.G. Stout, K.P. Staudhammer, J.L. Smith, Effectsof strain state and strain rate on deformation- induced transformationin 304 stainless-steel.Part I. Magnetic measurements and mechanicalbehavior, Metallurgical Transactions A-Physical Metallurgyand Materials Science, 1982,13(4):619-626.

[26] V. Shrinivas, S.K. Varma, L.E. Murr, Deformation-induced martensitic characteristics in 304stainless and 316-stainless steels during room-temperature rolling, Metallurgical and Materials Transactions A-Physical Metallurgy and Materials Science, 1995, 26(3):661-671.

[27] N. Hashimoto, S.J. Zinkle, A.F. Rowcliffe, J.P. Robertson,S. Jitsukawa, Deformation mechanisms in 316 stainless steel irradiated at $60^{\circ} \mathrm{C}$ and $330^{\circ} \mathrm{C}$, J. Nucl. Mater.,2000, 283$287: 528-534$

[28] J.W. Brooks, M.H. Loretto, R.E. Smallman, In situ observations of the formation of martensite in stainless steel, Acta Metall., 1979, 27:1829-1838.

[29] J.W. Brooks, M.H. Loretto, R.E. Smallman, Direct observations of martensite nuclei in stainless steel, Acta Metall., 1979,27:1839-1847.

[30] M. Eskandari, A. Najafizadeh, A. Kermanpur,Effect of strain-induced martensite on the formation of nanocrystalline 316Lstainless steel after cold rolling and annealing,Mater.Sci.Eng. A, 2009, 519:46-50.

[31]B.K. Choudhary. Influence of strain rate and temperature on tensile deformation and fracture 
behavior of type 316L(N) austenitic stainless steel.,Metallurgical and Materials Transactions A, $2014,45(1): 302-316$

[32] S. Sinha, J.Szpunar, N.A.P.KiranKumar, N.P.Gurao, Tensile deformation of 316L austenitic stainless steel using in-situ electron back scatter diffraction and crystal plasticity simulations. Mater.Sci.Eng. A, 2015, 637:48-55.

[33] Z.Z. Yuan, Q.X. Dai, X.N. Cheng, K.M. Chen, L. Pan, A.D. Wang. In situ SEM tensile test of high-nitrogen austenitic stainless steels, Materials Characterization, 2006,56 :79-83.

[34]A.Sato, K. Soma, T.Mori,Hardening due to pre-existing €-Martensite in an Fe-30Mn-1Si alloy single crystal, Acta Metall., 1982, 30:1901-1907

[35]V.Seetharaman, R.Krishnan,Influence of the martensitic transformation on the deformation behaviour of an AISI 316 stainless steel at low temperatures, J. Mater. Sci., 1981, 16: 523-530.

[36] D. Goodchild, W.T. Roberts, D.V. Wilson, Plastic deformation and phase transformation in textured austenitic stainless steel, Acta Metall., 1970, 18:1137-1145.

[37] T.S. Byun, E.H. Lee, J.D. Hunn, Plastic deformation in 316LN stainlesssteel-characterization of deformation microstructures,Journal of Nuclear Materials, 2003, 321:29-39.

[38] X.F. Li, J. Chen, L.Y. Ye, W. Ding, P.C. Song, The influence of strain rate on tensile characteristics of SUS304 metastable austenitic stainless steel, Acta Metallurgica Sinica (English Letters), 2013, 26(6):657-662

[39] X.F. Li, J.J. Li, W. Ding, S.J. Zhao, J. Chen, Stress relaxation in tensile deformation of 304 stainless steel, Journal of Materials Engineering and Performance, 2017, 26(2): 630-635

[40] X.Y. LI, Y.J. Wei, L. Lu, K. Lu, H.J. Gao, Dislocation nucleation governed softening and maximum strength in nano-twinned metals, Nature, 2010, 464: 877-880. 
Figures and captions:

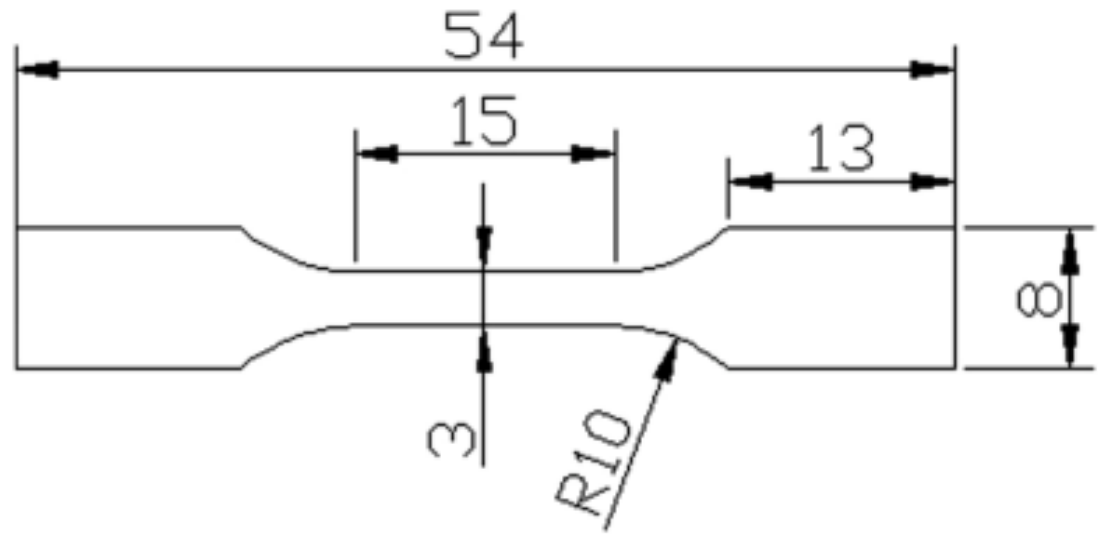

Fig. 1. Diagram of tensile test specimens. 


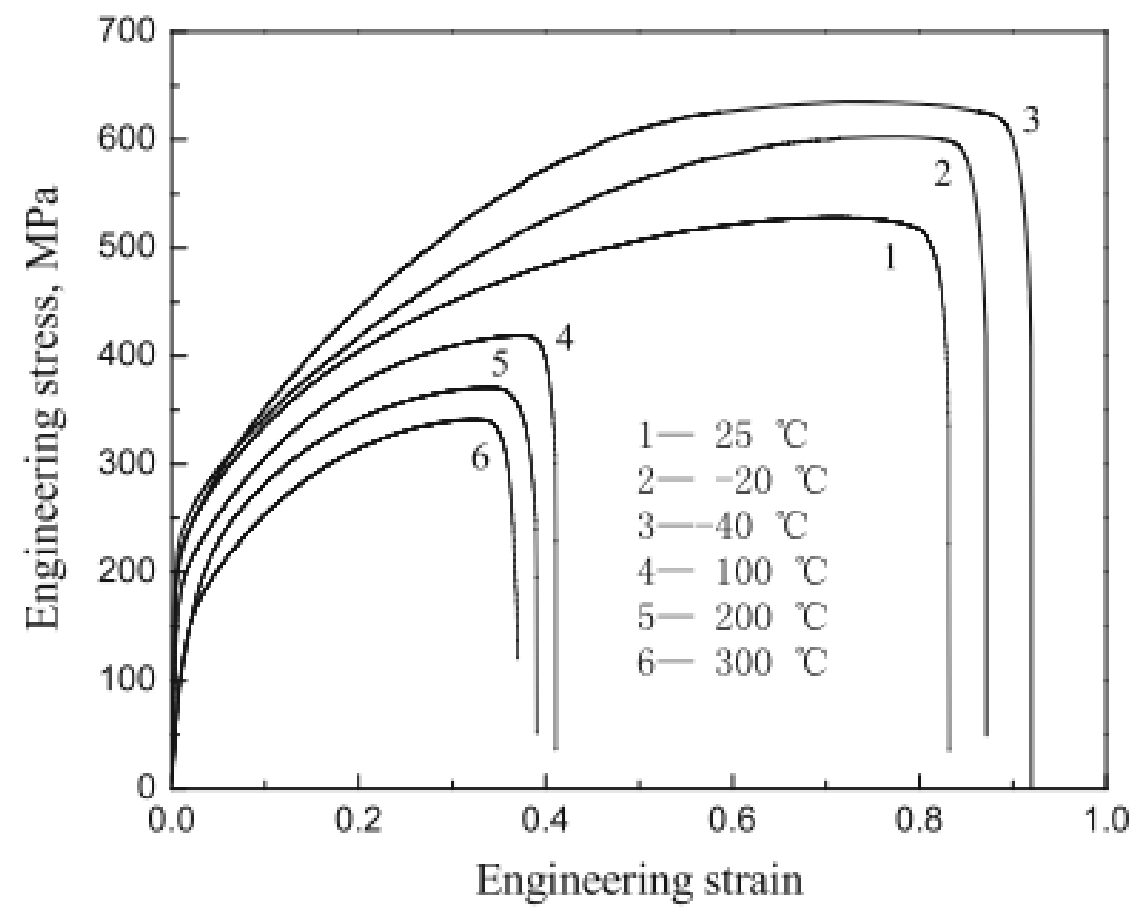

Fig.2.Engineering stress-strain curves of $316 \mathrm{LN}$ austenitic stainless steels under different temperatures.

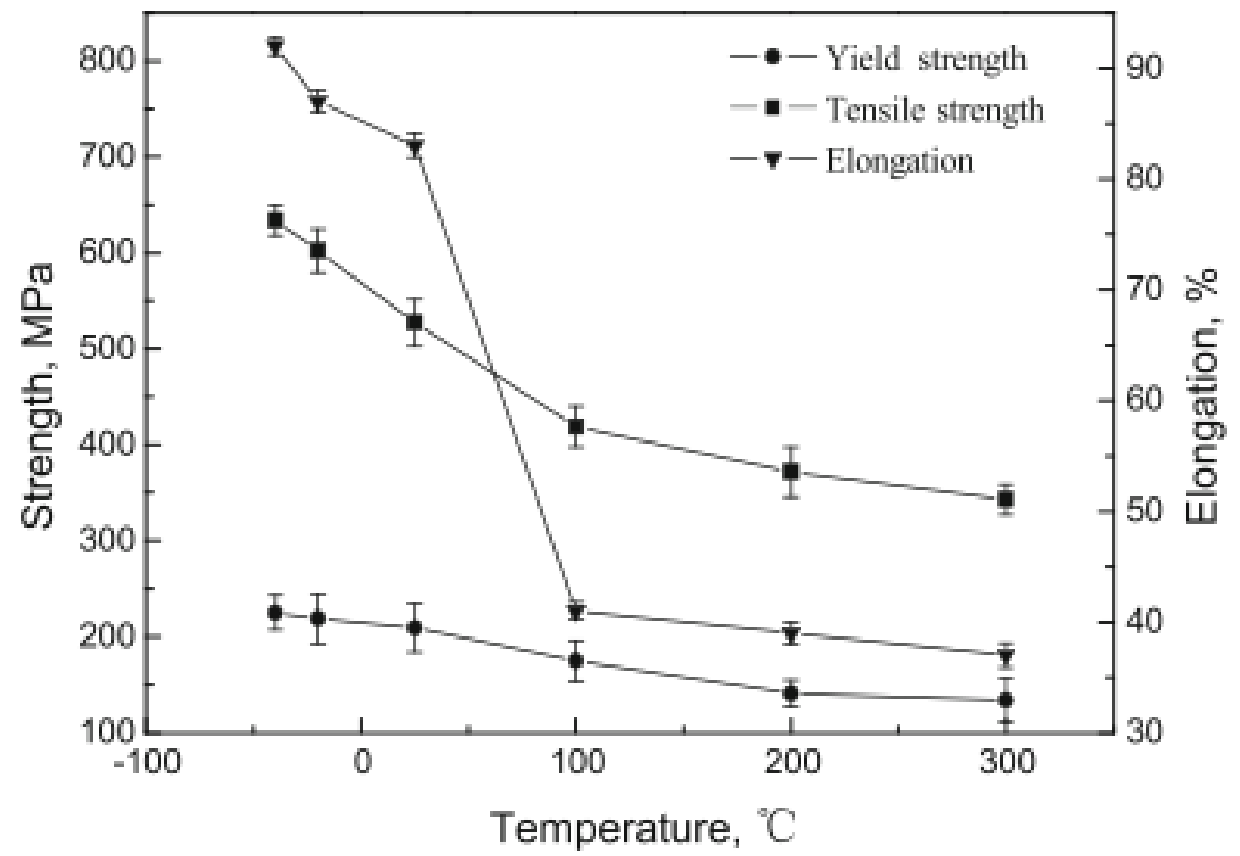

Fig. 3.Mechanical properties of the $316 \mathrm{LN}$ austenitic stainless steels under different temperatures. 

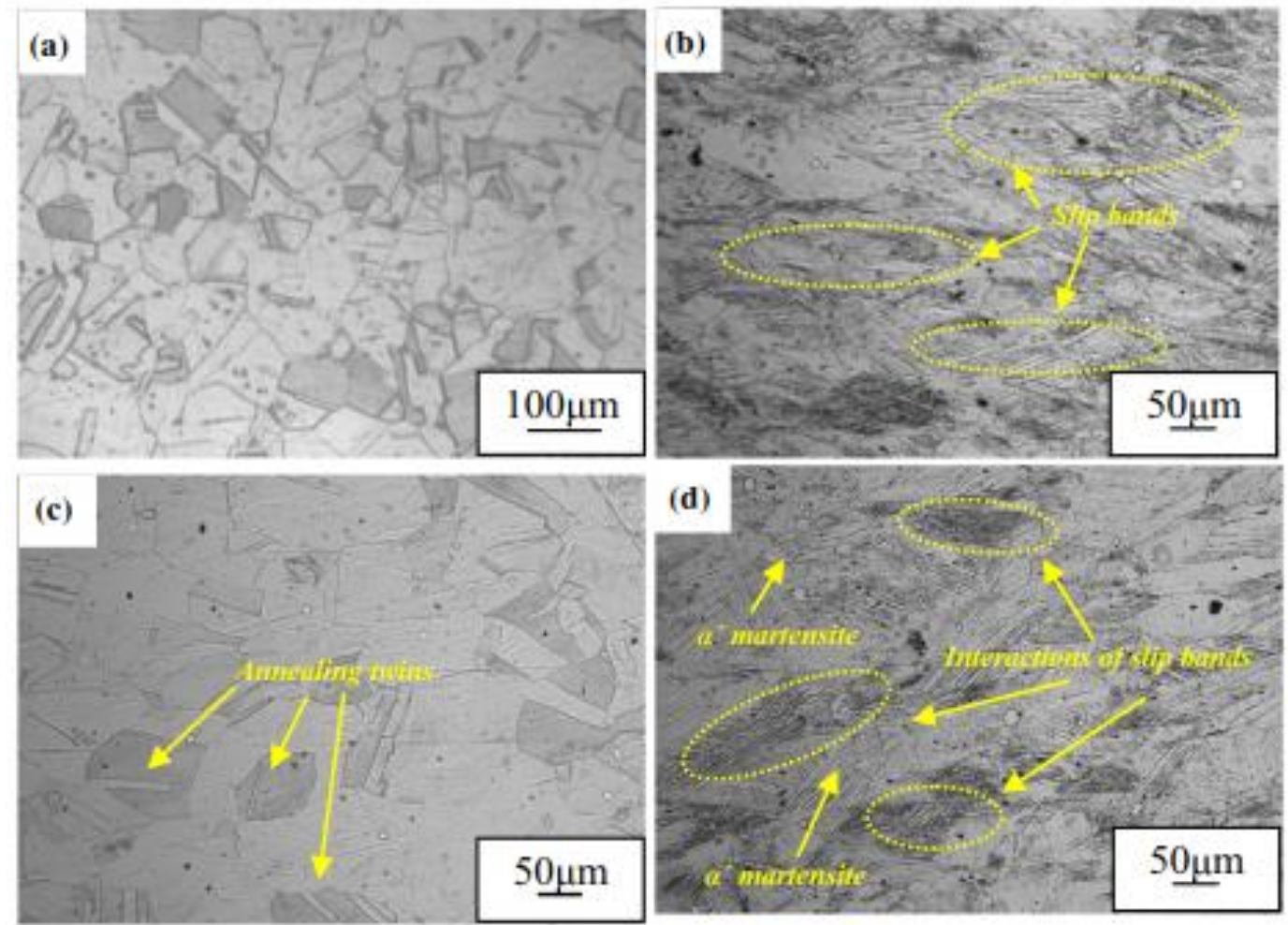

Fig.4.OM images of microstructure near the tensile fracture: (a) before tensile; (b)room temperature $\left(25^{\circ} \mathrm{C}\right) ;(\mathrm{c}) 300{ }^{\circ} \mathrm{C} ;(\mathrm{d})-40^{\circ} \mathrm{C}$. 

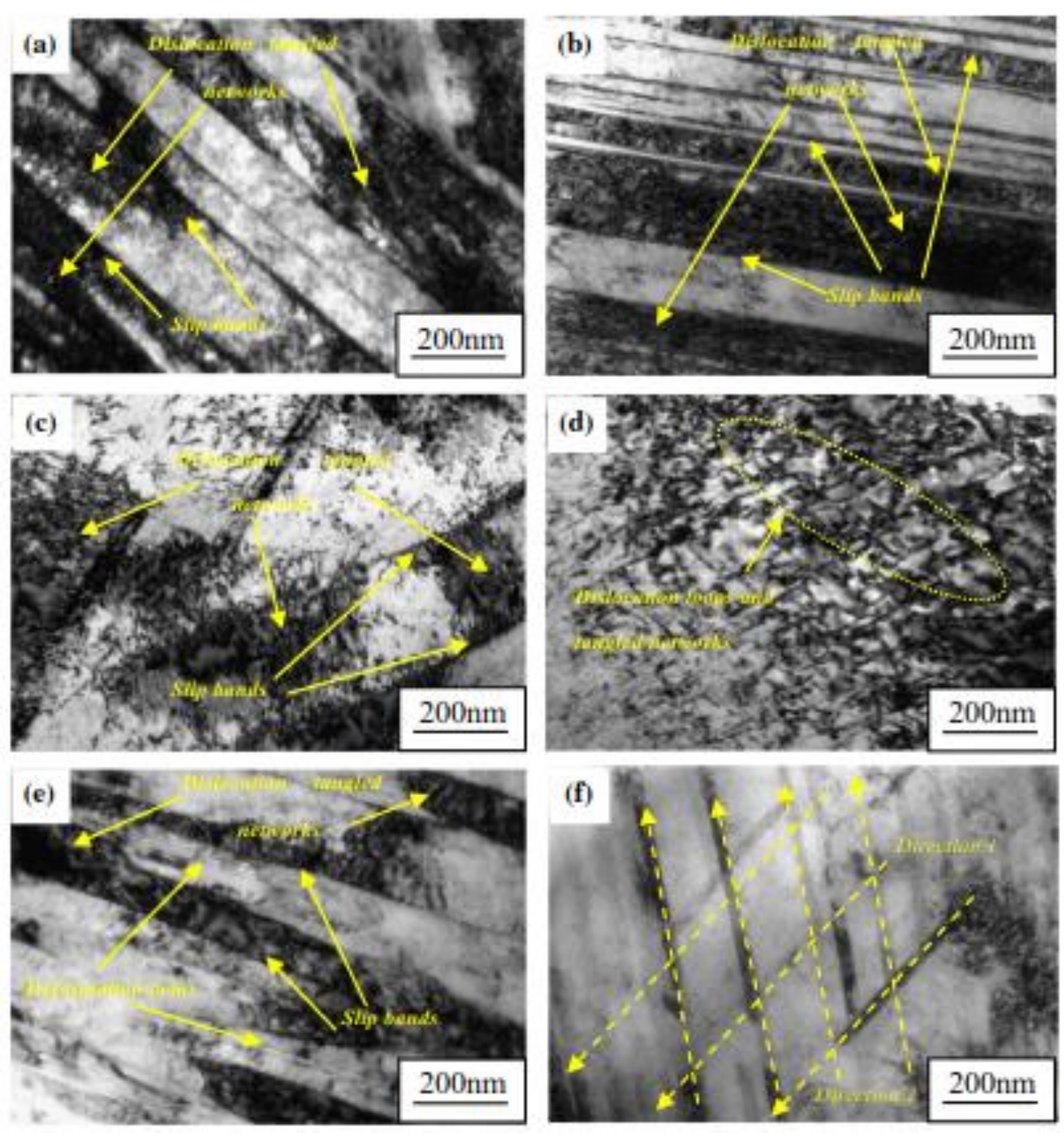

Fig.5. TEM images of microstructure near the tensile fracture: (a) and (b) room temperature $\left(25^{\circ} \mathrm{C}\right)$;

(c) and (d) $300^{\circ} \mathrm{C}$; (e) and (f) $-40^{\circ} \mathrm{C}$. 


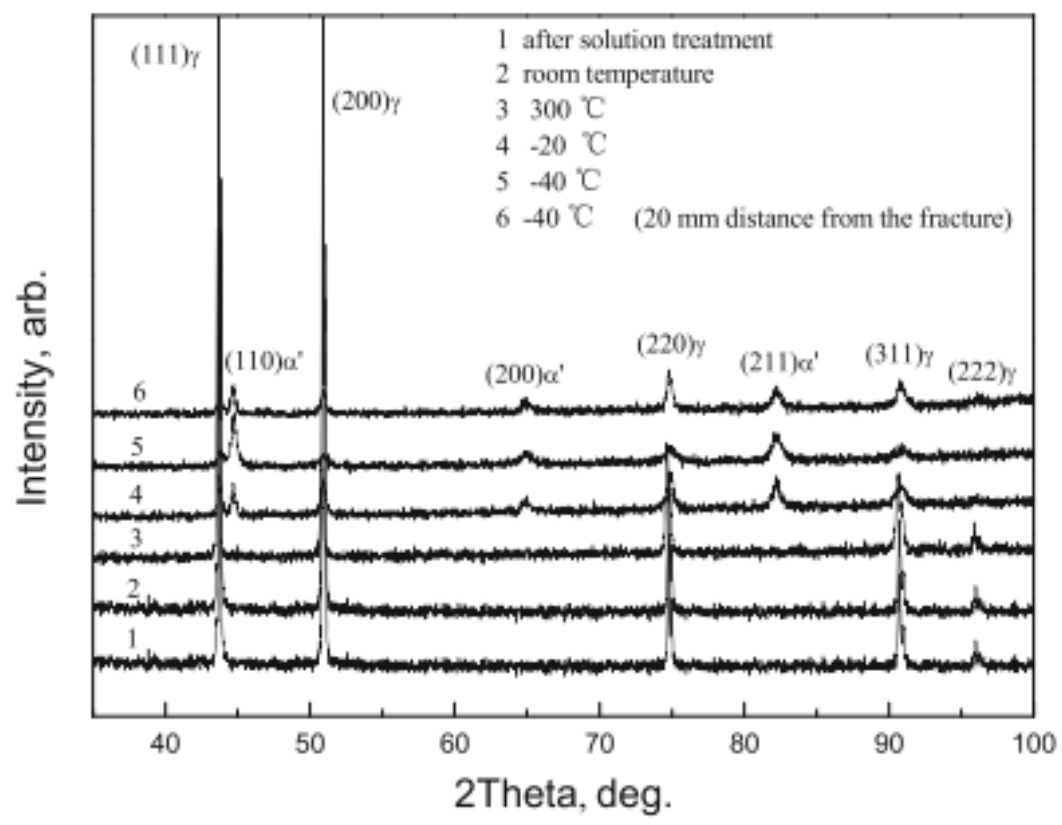

Fig. 6.XRD patterns of $316 \mathrm{LN}$ austenitic stainless steels after uniaxial tensile tests at different temperatures.
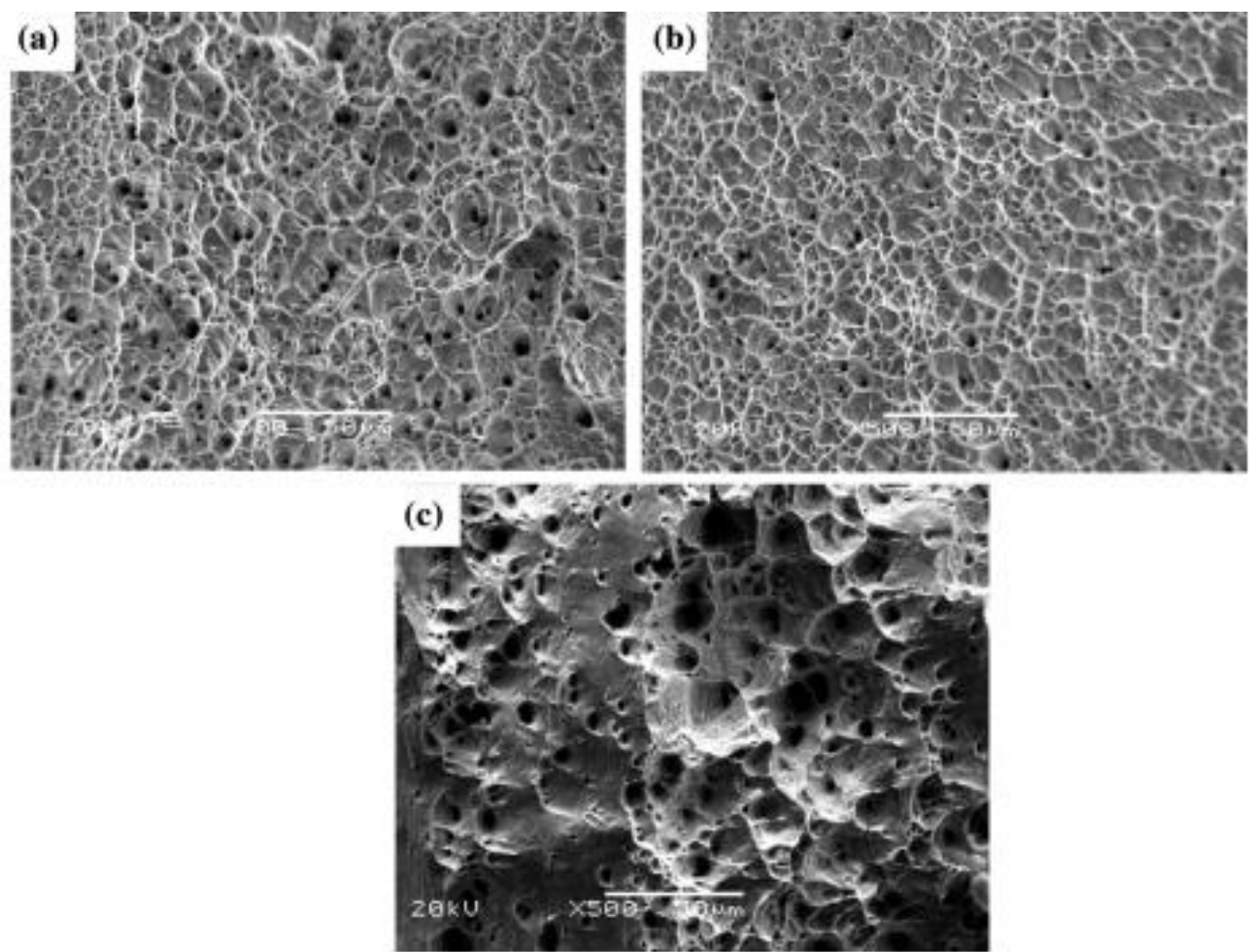

Fig. 7.Fractography of the $316 \mathrm{LN}$ austenitic stainless steels specimens tested at (a) $-20^{\circ} \mathrm{C}$; (b) room temperature $\left(25^{\circ} \mathrm{C}\right)$; (c) $300^{\circ} \mathrm{C}$. (perpendicular to tensile direction) 

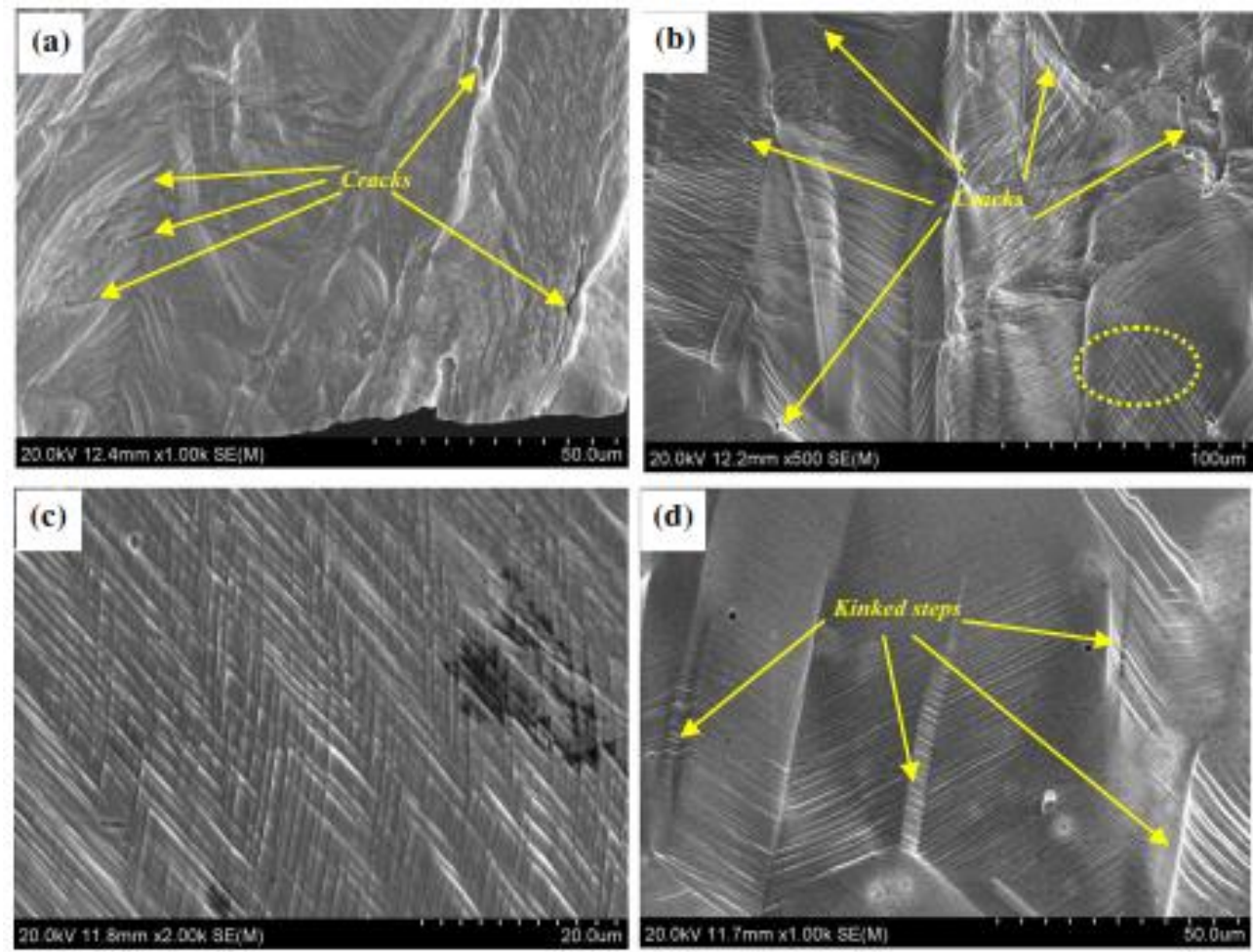

Fig. 8.Surface morphologyof the $316 \mathrm{LN}$ austenitic stainless steels specimens after tensile at room temperature. (a) near the fracture; (b) $10 \mathrm{~mm}$ distance from the fracture; (c) the magnification of the elliptical area of (b); (d) $20 \mathrm{~mm}$ distance from the fracture. (parallel to the tensile direction)

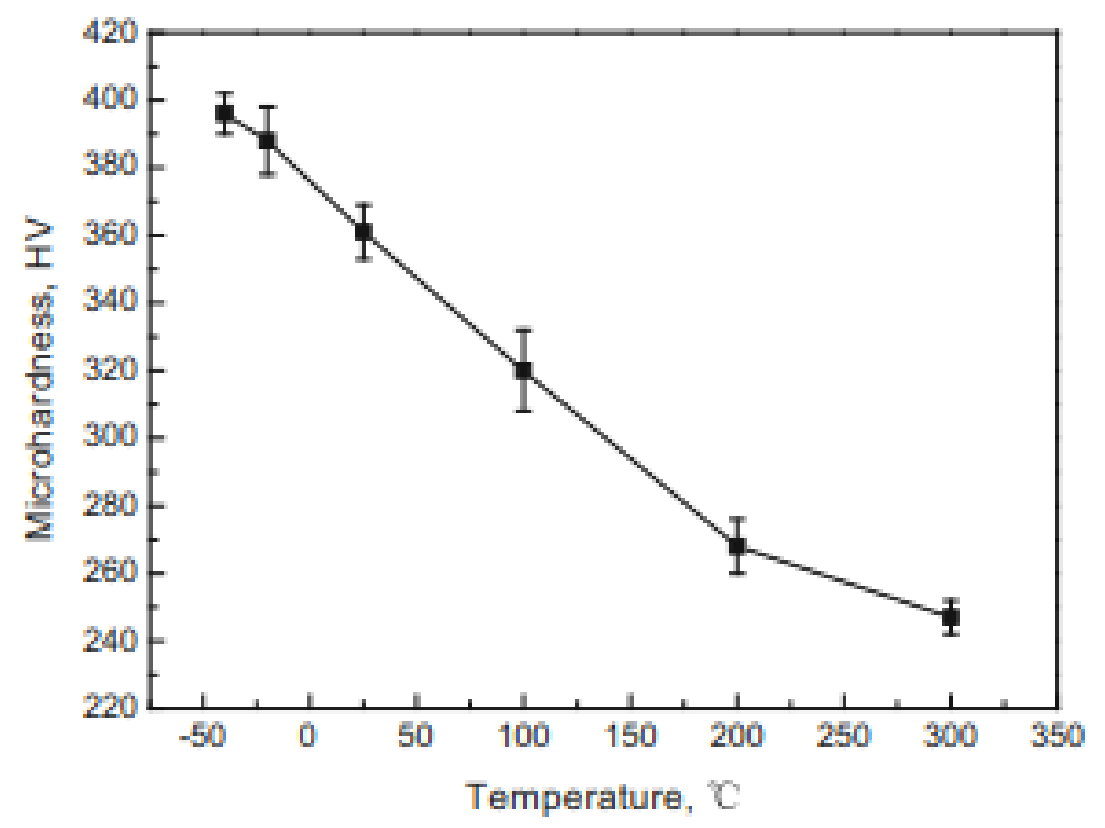

Fig. 9.Microhardness of the316LN austenitic stainless steels samples near tensile fracture. 


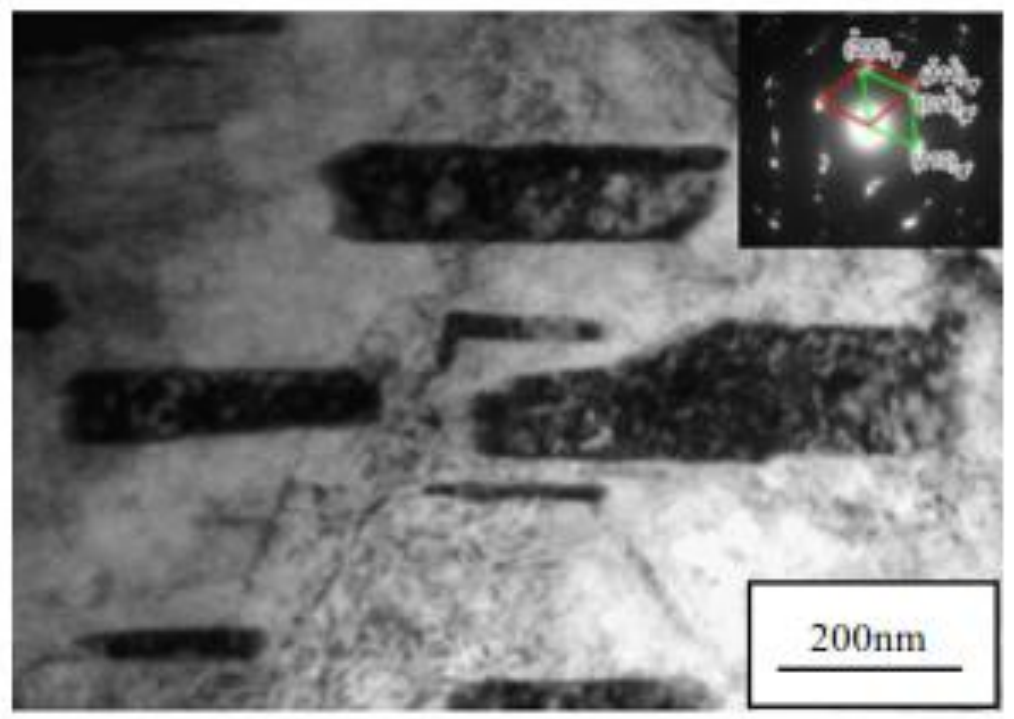

Fig. 10.Microstructure of the deformation-induced martensite.

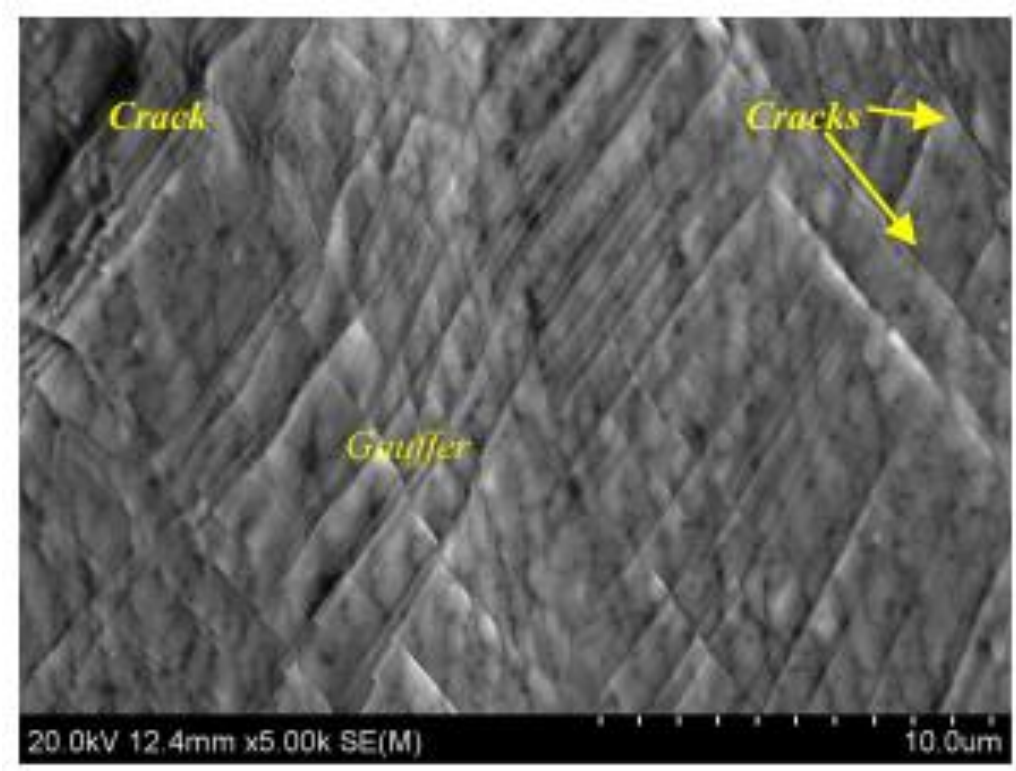

Fig.11. Cracks and gauffers produced by the interaction between twins. 